\title{
Methanol on Anatase $\mathrm{TiO}_{2}$ (101): Mechanistic Insights into Photocatalysis
}

\author{
Martin Setvin, ${ }^{*}{ }^{\dagger} \bigcirc$ Xiao Shi, ${ }^{\ddagger}$ Jan Hulva, ${ }^{\dagger}$ Thomas Simschitz, ${ }^{\dagger}$ Gareth S. Parkinson, ${ }^{\dagger}$ Michael Schmid, ${ }^{\dagger}$ \\ Cristiana Di Valentin, $*, \S \odot$ Annabella Selloni, ${ }^{\ddagger \odot}$ and Ulrike Diebold ${ }^{\dagger}$
}

\author{
${ }^{\dagger}$ Institute of Applied Physics, TU Wien, Wiedner Hauptstrasse 8-10/134, 1040 Vienna, Austria \\ ${ }^{\ddagger}$ Department of Chemistry, Princeton University, Frick Laboratory, Princeton, New Jersey 08544, United States \\ ${ }^{\S}$ Dipartimento di Scienza dei Materiali, Università di Milano-Bicocca, Via Cozzi 55, 20125 Milano, Italy
}

\author{
Supporting Information
}

\begin{abstract}
The photoactivity of methanol adsorbed on the anatase $\mathrm{TiO}_{2}$ (101) surface was studied by a combination of scanning tunneling microscopy (STM), temperature-programmed desorption (TPD), X-ray photoemission spectroscopy (XPS), and density functional theory (DFT) calculations. Isolated methanol molecules adsorbed at the anatase (101) surface show a negligible photoactivity. Two ways of methanol activation were found. First, methoxy groups formed by reaction of methanol with coadsorbed $\mathrm{O}_{2}$ molecules or terminal $\mathrm{OH}$ groups are photoactive, and they turn into formaldehyde upon UV illumination. The methoxy species show an unusual C 1 s core-level shift of $1.4 \mathrm{eV}$ compared to methanol; their chemical assignment was verified by DFT calculations with

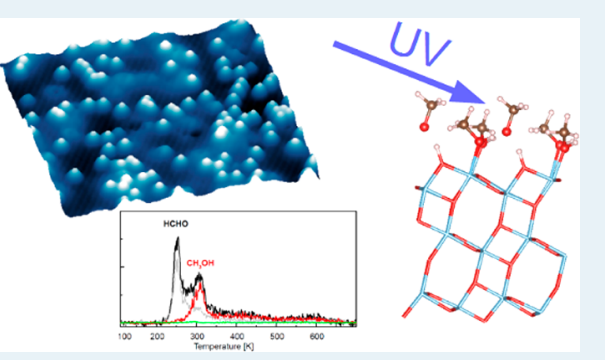
inclusion of final-state effects. The second way of methanol activation opens at methanol coverages above $0.5 \mathrm{monolayer}$ (ML), and methyl formate is produced in this reaction pathway. The adsorption of methanol in the coverage regime from 0 to $2 \mathrm{ML}$ is described in detail; it is key for understanding the photocatalytic behavior at high coverages. There, a hydrogen-bonding network is established in the adsorbed methanol layer, and consequently, methanol dissociation becomes energetically more favorable. DFT calculations show that dissociation of the methanol molecule is always the key requirement for hole transfer from the substrate to the adsorbed methanol. We show that the hydrogen-bonding network established in the methanol layer dramatically changes the kinetics of proton transfer during the photoreaction.
\end{abstract}

KEYWORDS: anatase, $\mathrm{TiO}_{2}$, methanol, photocatalysis, STM, DFT, XPS, TPD

\section{INTRODUCTION}

Photocatalysis is currently at the center of scientific interest as a potential route to efficient light harvesting for the production of transportable fuels. ${ }^{1-3}$ However, transfer of photocatalysis into applications is hampered by the low quantum efficiency of the whole process, which typically does not exceed $10 \%$. The detailed mechanisms leading to efficient photocatalytic reactions are still a subject of an intensive debate, despite more than 40 years of research in the field. ${ }^{4}$

$\mathrm{TiO}_{2}$ is a prototypical photocatalytic material. It crystallizes in two main forms, rutile and anatase, ${ }^{5}$ where the metastable anatase is often considered more photoactive. ${ }^{6}$ Methanol is a molecule representing a class of simple organic molecules, which bind via their oxygen atom in a monodentate configuration. As a model system, methanol on $\mathrm{TiO}_{2}$ has thus attracted significant attention from both experiment and theory in the past decades. ${ }^{7-18}$ The experimental work mainly focused on the rutile (110) surface, though. It has been demonstrated by scanning tunneling microscopy (STM) that isolated methanol ${ }^{19}$ (or water) ${ }^{16}$ molecules adsorbed on $\mathrm{TiO}_{2}$ rutile (110) can be split by UV light. Coverage-dependent investigations on the rutile (110) surface showed that the photoactivity of methanol decreases with an increasing coverage. $^{20}$ (This behavior is opposite to the results on anatase, presented in this work.) It was further reported that the formation of methoxy species significantly increases the photocatalytic activity. ${ }^{8}$ Methoxy groups on the rutile $\mathrm{TiO}_{2}$ (110) have been previously obtained either by direct reaction of methanol with surface oxygen vacancies ${ }^{9}$ or by reaction of methanol with coadsorbed oxygen.,

Here we investigate the mechanisms of methanol photoactivation on anatase $\mathrm{TiO}_{2}$ (101), which is the most typical surface found in commercial catalysts. Unlike the well-studied rutile (110) surface, ${ }^{5}$ anatase (101) does not contain surface oxygen vacancies $\left(\mathrm{V}_{\mathrm{O}} \mathrm{s}\right){ }^{21-23}$ which prevents bond cleavage within the methanol molecule from direct interaction with the highly reactive $\mathrm{V}_{\mathrm{O}} \mathrm{s}$. This makes the surface chemistry on anatase (101) closer to real photocatalytic conditions, since the surface $\mathrm{V}_{\mathrm{O}} \mathrm{s}$ are not expected to exist outside ultrahigh vacuum (UHV).

We first analyze in detail the adsorption of methanol in the coverage regime from 0 to 2 monolayers (ML), which is the

Received: June 19, 2017

Revised: $\quad$ August 29, 2017

Published: September 7, 2017 
key for understanding its photocatalytic reactions. Next we show that single, isolated methanol molecules show only negligible photocatalytic activity. Our calculations indicate that the main impediment for photooxidation of methanol lies in the hole transfer from the substrate: Methanol must first dissociate (form a methoxy group), and only then the hole transfer becomes energetically favorable. We achieved the dissociation either by reactions with external species coadsorbed at the surface $\left(\mathrm{O}_{2}\right.$ molecules or terminal $\mathrm{OH}$ groups) or by intramolecular interactions in the methanol layer, which occur at higher coverages. The first mechanism (reaction with $\mathrm{O}_{2}$ ) has been previously reported on the rutile (110) surface. ${ }^{7,8}$ The second mechanism is closely related to hydrogen bonding between methanol molecules. It is known that hydrogen bonding plays a significant role in biological systems, ${ }^{24,25}$ catalytic reactions, ${ }^{26}$ and possibly also in photocatalysis. ${ }^{27}$ Here we show that the hydrogen bonding between methanol molecules can alter the energy balance for thermal dissociation of the molecule and, consequently, change the energy balance for hole transfer onto the molecule and activate the molecule for photocatalysis.

In this work, we use scanning tunneling microscopy (STM) to observe photocatalytic processes at the atomic scale. STM is an excellent tool for direct observation of species and photoinduced changes, but its main disadvantage is the lack of chemical sensitivity. For unambiguous chemical identification of the adsorbed species, we use area-averaging spectroscopic techniques: X-ray photoelectron spectroscopy (XPS) and temperature-programmed desorption (TPD). Density functional theory (DFT) calculations provide detailed insights into the reaction pathways and mechanisms. We also calculate and discuss XPS core-level shifts of the methanol and methoxy C 1s peaks, because the experimentally observed chemical shift between these two species is significantly higher than observed on other oxide surfaces.

\section{EXPERIMENTAL AND COMPUTATIONAL DETAILS}

STM measurements were performed at $T=6 \mathrm{~K}$ or $T=80 \mathrm{~K}$ in a UHV chamber with a base pressure below $1 \times 10^{-11} \mathrm{mbar}$, equipped with a commercial Omicron LT-STM head. Controlled low-temperature annealing of the sample was performed in a manipulator cooled by flowing nitrogen gas. The temperature was measured by a K-type thermocouple attached to the sample holder. We estimate that the quoted temperatures are accurate within $\pm 10 \mathrm{~K}$. Electrochemically etched W STM tips were cleaned by sputtering or selfsputtering $^{28}$ in $\mathrm{Ar}$ and treated on a $\mathrm{Cu}$ (100) or $\mathrm{Au}$ (110) surface to obtain a reproducible, metallic tip condition. We used a single-crystalline mineral anatase $\mathrm{TiO}_{2}(101)$ sample, naturally doped by $1 \% \mathrm{Nb}^{23}$ The surface was prepared by exsitu cleaving or polishing (both types were used) and subsequent cleaning in vacuum by cycles of $\mathrm{Ar}^{+}$sputtering (1 $\mathrm{keV}$ ) and annealing to $950 \mathrm{~K}^{29} \mathrm{~A} \mathrm{Hg}$ discharge lamp (Oriel Instruments) was used for illuminating the surface by UV light. The incident photon flux was $1.3 \times 10^{16} \mathrm{~cm}^{-2} \mathrm{~s}^{-1}$. The light was introduced to the UHV chamber via a quartz window into the STM cryostat. The sample temperature during the illumination was below $20 \mathrm{~K}$ for measurements performed at $\mathrm{LHe}$ temperature, and $81 \mathrm{~K}$ for measurements performed at $\mathrm{LN}_{2}$ temperature. The tip was retracted by $\sim 100 \mu \mathrm{m}$ during the UV irradiation.

The TPD measurements were performed in a separate UHV system $^{30}$ with a base pressure of $5 \times 10^{-11}$ mbar using a
HIDEN quadrupole mass spectrometer in a line-of-sight configuration. Here the anatase sample was mounted on a Ta back plate, cooled by a Janis ST-400 UHV liquid He flow cryostat, and heated by direct current through the back plate. The temperature was measured by a K-type thermocouple spotwelded to the sample plate, and calibrated using multilayer desorption of several gases $\left(\mathrm{O}_{2}, \mathrm{H}_{2} \mathrm{O}, \mathrm{CO}\right)$. The resulting uncertainty in the absolute temperature reading is estimated to be $\pm 3 \mathrm{~K}$ (increasing up to $\pm 10 \mathrm{~K}$ at temperatures below $\sim 40$ $\mathrm{K})$. During the TPD measurements, the sample was biased at $-100 \mathrm{~V}$ to prevent electrons from the quadrupole's filament reaching the sample surface. Gases were dosed by an effusive molecular beam with a hat-shape profile. ${ }^{30,31}$ This produces a beam spot of $\approx 3.5 \mathrm{~mm}$ diameter at the sample (sample size $4 \times$ $6 \mathrm{~mm}^{2}$ ) and also allows us to determine the gas dose with an accuracy better than $10 \%$. One monolayer (ML) of methanol corresponds to a dosage of 1.6 Langmuir (L) (taking into account the measured sticking coefficient of 0.85 ). Only the $\mathrm{TiO}_{2}(101)$ surface was exposed to the molecular beam. The dose rate under these conditions is approximately $1.2 \mathrm{ML} / \mathrm{min}$. For the TPD measurements a linear temperature ramp of $1 \mathrm{~K} / \mathrm{s}$ was used.

XPS spectra were measured in the same vacuum system with a hemispherical electrostatic energy analyzer (SPECS Phoibos 150 ), using a monochromatized $\mathrm{Al} \mathrm{K} \alpha \mathrm{X}$-ray source (SPECS Focus 500). Data were recorded at a sample temperature of $T=$ $34 \mathrm{~K}$. Any influence of the X-rays and contamination from the residual gas was carefully checked by TPD spectra recorded after the XPS data were taken; no radiation-induced damage was observed. XPS was measured under a $60^{\circ}$ exit angle off normal.

Spin-polarized DFT calculations were performed within the plane-wave pseudopotential scheme as implemented in the Quantum ESPRESSO package. ${ }^{32}$ We used the generalized gradient approximation of Perdew, Burke and Ernzerhof $(\mathrm{PBE})^{33}$ with the addition of on-site Hubbard $U$ repulsion ${ }^{34}$ on the Ti $3 \mathrm{~d}$ orbitals. We took $U=3.9 \mathrm{eV}$, as given by cRPA calculations. ${ }^{35}$ Electron-ion interactions were described using ultrasoft pseudopotentials. ${ }^{36} \mathrm{We}$ expanded the electronic states in plane waves using a kinetic-energy cutoff of 25.0 (200.0) Ry for the smooth part of the wave function (augmented charge density). The anatase (101) surface was modeled using a repeated-slab geometry with lattice parameters optimized at the PBE level and a vacuum width of $18 \AA$ between adjacent slabs. We considered a slab of $3 \mathrm{TiO}_{2}$ trilayers, with various rectangular surface supercells, notably $(1 \times 2)$, corresponding to a surface area of $10.21 \times 7.55 \AA^{2},(1 \times 3)$, and $(1 \times 4)$. In all cases, only the $\Gamma$-point was used to sample the Brillouin zone. Structural optimizations were performed relaxing all atomic positions until residual forces were smaller than $0.05 \mathrm{eV} / \AA$. Energy barriers between different adsorption structures were estimated using the nudged-elastic band (NEB) method, ${ }^{37}$ and pathways were relaxed until forces converged below $0.05 \mathrm{eV} / \AA$. Constant-density $\left(10^{-5}\right.$ electrons per bohr $\left.{ }^{3}\right)$ STM images were calculated by integrating the local density of states in an energy window of $\sim 2.5 \mathrm{eV}$ from the conduction band minimum.

Reaction pathways in the presence of a photoexcited hole were investigated by means of the CRYSTAL06 package ${ }^{38}$ where the Kohn-Sham orbitals are expanded in Gaussian type orbitals (the all-electron basis sets are O 8-411(d1), Ti 86411 (d41), H 311(p1), C 6-311(d11)). The hybrid B3LYP functional ${ }^{39-41}$ was employed. We modeled the anatase (101) $\mathrm{TiO}_{2}$ surface using a slab of three triatomic layers with 72 
atoms and $(1 \times 2)$ periodicity along the $[10 \overline{1}]$ and $[010]$ directions corresponding to a surface area $10.48 \times 7.59 \AA^{2}$; we did not use periodic boundary condition in the direction perpendicular to the surface. The k-space sampling for the geometry optimizations included four k-points. Structural optimizations were performed relaxing all atomic positions until residual forces were smaller than $0.012 \mathrm{eV} / \mathrm{bohr}$. In order to evaluate activation barriers along a reaction pathway, we performed a series of constrained optimizations in which one internal coordinate was kept fixed at different values, whereas the remaining coordinates were fully relaxed until forces converged below $0.012 \mathrm{eV} / \mathrm{bohr}$.

\section{RESULTS}

Methanol Adsorption. We first discuss in detail the methanol adsorption configurations as a function of coverage. Figure 1a shows TPD spectra in the coverage range from
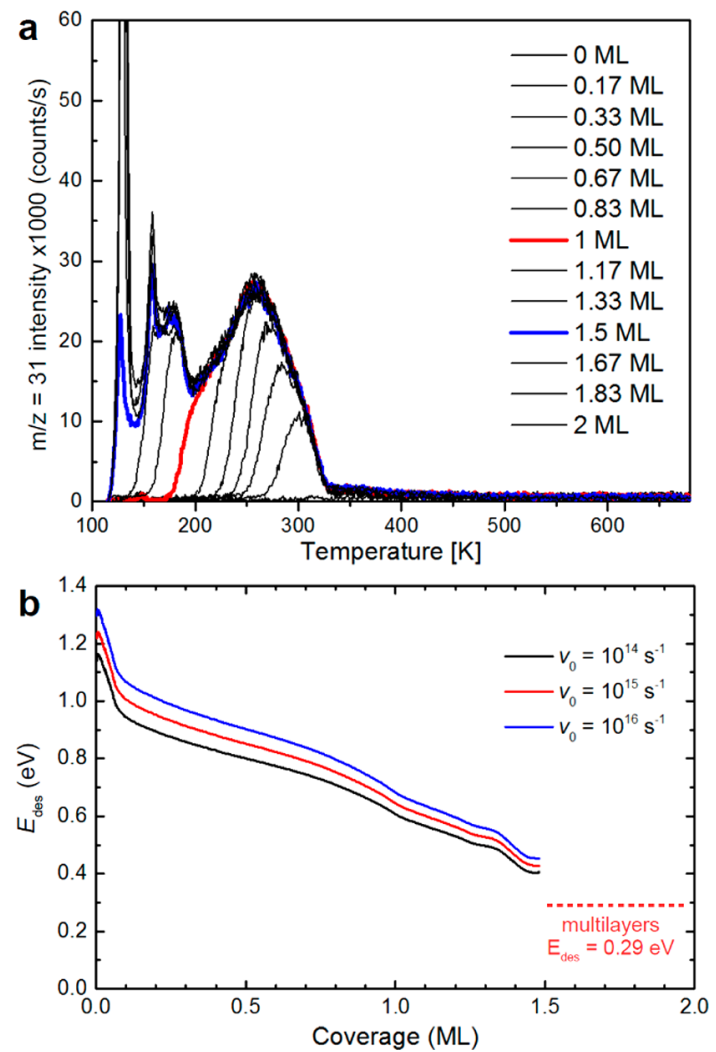

Figure 1. (a) TPD spectra of methanol on the anatase (101) surface. One monolayer $(\mathrm{ML})$ is defined as one molecule per surface $\mathrm{Ti}_{5 \mathrm{c}}$ atom. (b) Coverage-dependent adsorption energies, obtained from the results shown in (a) by the inversion analysis method. ${ }^{43}$

0 to $2 \mathrm{ML}$ (one monolayer is defined as one molecule per a surface $\mathrm{Ti}_{5 \mathrm{c}}$ atom). The first-monolayer peak is broad, ranging from 200 to $330 \mathrm{~K}$. It is followed by a sharp double peak centered at temperatures of 157 to $180 \mathrm{~K}$, which contains another $0.5 \mathrm{ML}$ of methanol. All methanol molecules above 1.5 ML have the same desorption energy corresponding to multilayer adsorption, causing the desorption peak at $127 \mathrm{~K}$. When the anatase surface was cleaned properly, no desorption peaks were detected above $330 \mathrm{~K}$ (sample cleanliness was verified by STM prior to inserting the sample into the TPD chamber). This indicates that the previously reported dissociation into methoxy ${ }^{42}$ at $620 \mathrm{~K}$ possibly originated from dissociation at extrinsic defects. The TPD spectra were analyzed by the inversion analysis technique, as described in ref 43 . We assumed the first-order desorption mechanism with a coverage-dependent adsorption energy and a constant frequency prefactor (thus neglecting entropic contributions to desorption). Results are shown in Figure 1b. The best fits were obtained for frequency prefactors ranging from $10^{14}$ to $10^{16} \mathrm{~s}^{-1}$, which is the range typically reported for methanol. ${ }^{43-45}$

Adsorption of methanol on the anatase (101) surface has been investigated previously by TPD and XPS, ${ }^{46}$ and computationally by DFT and molecular dynamics simulations. ${ }^{47}$ The results indicated that the amount of methanol in the first layer is above $1 \mathrm{ML}$, and the XPS data of the $\mathrm{O}$ 1s peak indicated that hydrogen bonding plays an important role in the first layer. We have repeated all calculations using thicker slabs and different, that is, $(1 \times 2),(1 \times 3)$, and $(1 \times 4)$, surface supercells, considering also the effect of donor dopants (subsurface $\mathrm{Nb}$ ) and comparing the results of pure PBE and $\mathrm{PBE}+\mathrm{U}$ calculations. Results of a representative set of $\mathrm{PBE}+U$ calculations are shown in Figure 2; these are coveragedependent adsorption configurations obtained using a $(1 \times$ 2) surface supercell, so that $1 \mathrm{ML}$ corresponds to four molecules per DFT unit cell, one molecule per surface Ti atom.

At low coverages, the methanol molecule binds with its $\mathrm{O}$ atom to a surface $\mathrm{Ti}_{5 c}$ atom, and forms an additional weak hydrogen bond ( $2.48 \AA$ length) to the surface $\mathrm{O}_{2 \mathrm{c}}$ atom (see Figure $2 \mathrm{a})$. For two molecules per DFT supercell (0.5 ML, Figure $2 \mathrm{~b})$, the most favorable adsorption configuration still consists of two molecules in the original monodentate configuration. However, the adsorption energy is almost identical to that of an alternative configuration, where one of the molecules is bound via two hydrogen bonds-one toward the surface, and one toward the neighboring methanol molecule (strong $\mathrm{H}$ bonds, 1.54-1.58 ̊). At one monolayer (Figure 2c), the most favorable adsorption configuration has two molecules bound to the surface $\mathrm{Ti}_{5 \mathrm{c}}$ atoms, plus two molecules bound only via $\mathrm{H}$-bonds. This configuration is more favorable than binding all molecules to the surface $\mathrm{Ti}_{5 \mathrm{c}}$ atoms. Up to $1 \mathrm{ML}$, the adsorption energy changes only slightly with coverage; this is in agreement with TPD measurements, where a single broad peak is detected. Adsorption of $1.5 \mathrm{ML}$ results in filling the remaining $\mathrm{Ti}_{5 \mathrm{c}}$ sites, though the adsorption is significantly weaker-the energy gain when adding the last two molecules is only $0.48 \mathrm{eV}$ per molecule, much less than the adsorption energy in the first monolayer $(0.70$ to $0.74 \mathrm{eV})$. This again agrees with the TPD data, where we observe distinct peaks in the range from 1 to $1.5 \mathrm{ML}$. Further increase of the coverage above 1.5 ML (see Figure 2e) results in adsorption in the second layer, where the additional molecules are only weakly bound, with an energy corresponding to $0.24 \mathrm{eV}$. This again shows an excellent agreement with the TPD data.

It is important to note that methanol dissociation becomes increasingly favorable with increasing coverage-see the bottom row in Figure 2. For a single molecule, the dissociated state is $0.21 \mathrm{eV}$ less favorable than the molecular adsorption. At higher coverages, the energy cost for dissociation decreases. This effect is associated with formation of a hydrogen-bond network in the layer. The presence of hydrogen bonds is in agreement with previous XPS data; ${ }^{46}$ here the O 1 s peak of the methanol molecule shifts toward lower binding energies at coverages above $0.5 \mathrm{ML}$, which is a characteristic feature associated with $\mathrm{H}$-bond donation into these atoms. ${ }^{48}$ 
(a) $0.25 \mathrm{ML}$
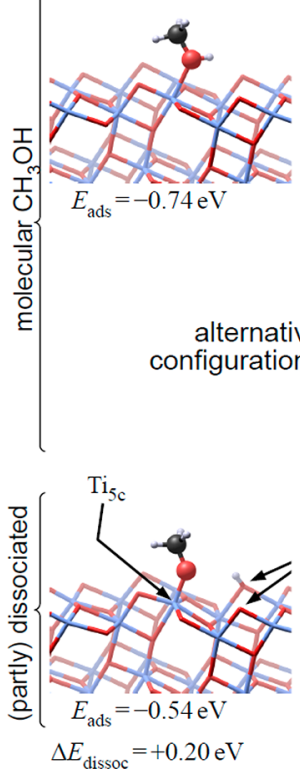

(b) $0.5 \mathrm{ML}$

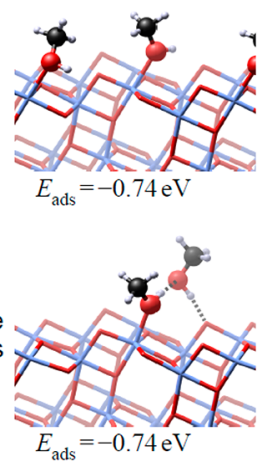

$\mathrm{O}_{2 \mathrm{c}}$ (bridging oxygen) (c) $1.0 \mathrm{ML}$
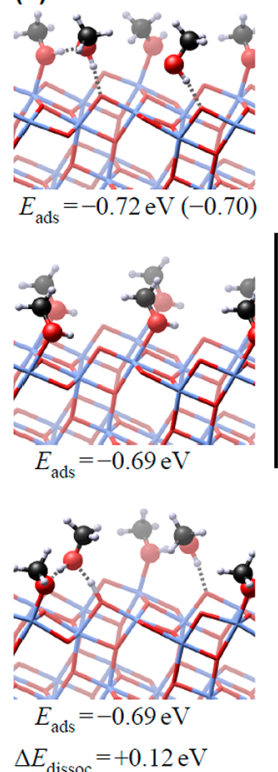

(d) $1.5 \mathrm{ML}$

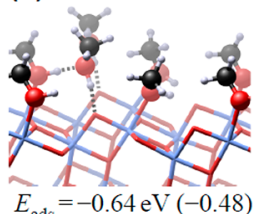

$E_{\text {ads }}=-0.64 \mathrm{eV}(-0.48)$

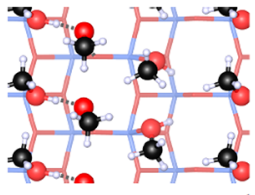

top view

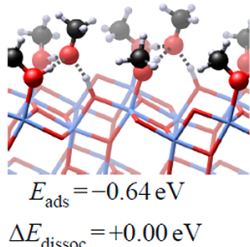

(e) $2.0 \mathrm{ML}$

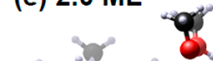

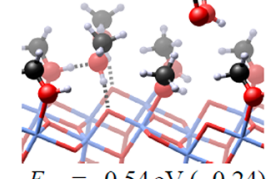

$E_{\text {ads }}=-0.54 \mathrm{eV}(-0.24)$

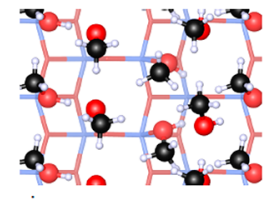

Figure 2. Calculated adsorption configurations of methanol at different coverages. The top row shows the most favorable adsorption configuration found at each coverage. The adsorption weakens with increasing coverage; $E_{\text {ads }}$ is the average adsorption energy per molecule, while the numbers in brackets denote the adsorption energy of the last molecule added to the slab (relevant for comparison with the TPD results in Figure 1). The second row shows selected alternative (less favorable) adsorption configurations. The last row shows a dissociated methanol molecule (energetically unfavorable except for $1.5 \mathrm{ML}$ ); note that dissociation becomes energetically more favorable with increasing coverage.

Calculations performed on larger slabs or in the presence of dopants show small quantitative differences from the values in Figure 2, while the qualitative behavior is already fully described by the $(1 \times 2)$ cell. We note that the increased tendency for dissociation into methoxy species with the coverage is opposite to the behavior reported on the rutile (110) surface. $^{49}$

Photoactivity of Isolated Methanol Molecules. We first examine the photoactivity of adsorbed methanol molecules in the dilute coverage limit (see Figure 3). In STM images, the molecule appears as a single, bright spot centered near a $\mathrm{Ti}_{5 \mathrm{c}}$ atom (inset in Figure 3a), with a typical apparent height of $\sim 120 \mathrm{pm}$. This is in agreement with the calculated adsorption configuration in Figure 2a. We have exposed the adsorbed methanol molecules to high doses of UV light. Figure $1 \mathrm{a}, \mathrm{b}$ shows the same area before and after $70 \mathrm{~min}$ UV irradiation. No change is noticeable; the molecules are essentially "photoblind". Hole transfer to isolated undissociated methanol molecules is not favored and was not observed in our calculations. This will be further discussed later in the manuscript, where low- and high-coverage results will be compared.

Reaction with Terminal $(\mathrm{OH})^{-}$Groups. It is known from previous studies that the photoactivity of methanol increases after partial dissociation into a methoxy group; on the rutile (110) surface, this was typically achieved by reacting it with coadsorbed oxygen ${ }^{8}$ or by reaction with oxygen vacancies. ${ }^{9}$ In the case of the anatase (101) surface, $\mathrm{O}_{2}$ adsorption is a complex process with multiple adsorption configurations. ${ }^{23,50-52}$ In order to simplify the reaction process, here we consider terminal $(\mathrm{OH})^{-}$groups (i.e., $\mathrm{OH}$ groups bound to surface $\mathrm{Ti}_{5 \mathrm{c}}$ atoms) instead of adsorbed $\mathrm{O}_{2}$. Results for the reaction with $\mathrm{O}_{2}$ are essentially identical (see Figures S1-S3). Reaction of methanol with terminal $(\mathrm{OH})^{-}$groups is imaged step-by-step by STM in Figure 4. DFT results for the same
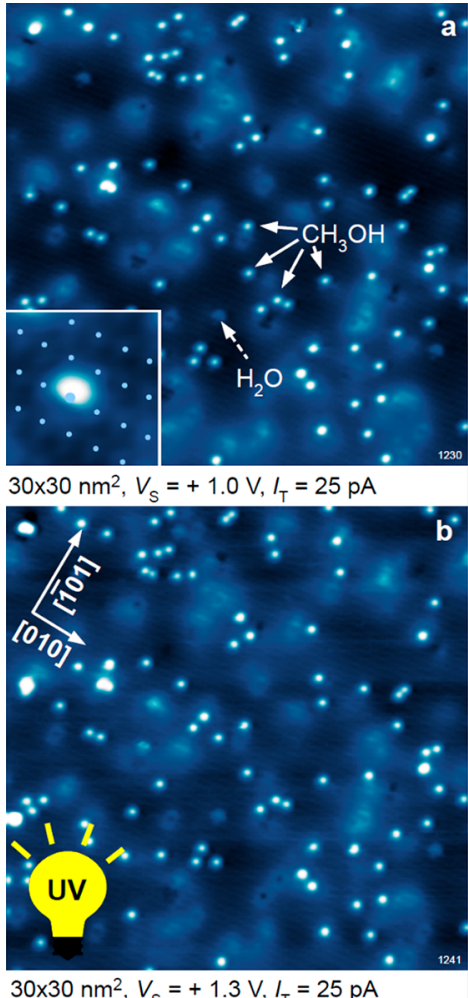

Figure 3. STM results of methanol on anatase (101). (a) $0.03 \mathrm{ML}$ methanol dosed surface at $T=100 \mathrm{~K}$, scanned at $T=80 \mathrm{~K}$. The inset shows a detail of a single molecule; positions of surface $\mathrm{Ti}_{5 c}$ atoms are marked. (b) The same area after $70 \mathrm{~min}$ of UV irradiation. The methanol molecules do not undergo any changes.

reaction sequence are shown in Figure 5. Chemical identification of all the species is confirmed by XPS in Figure 6. 


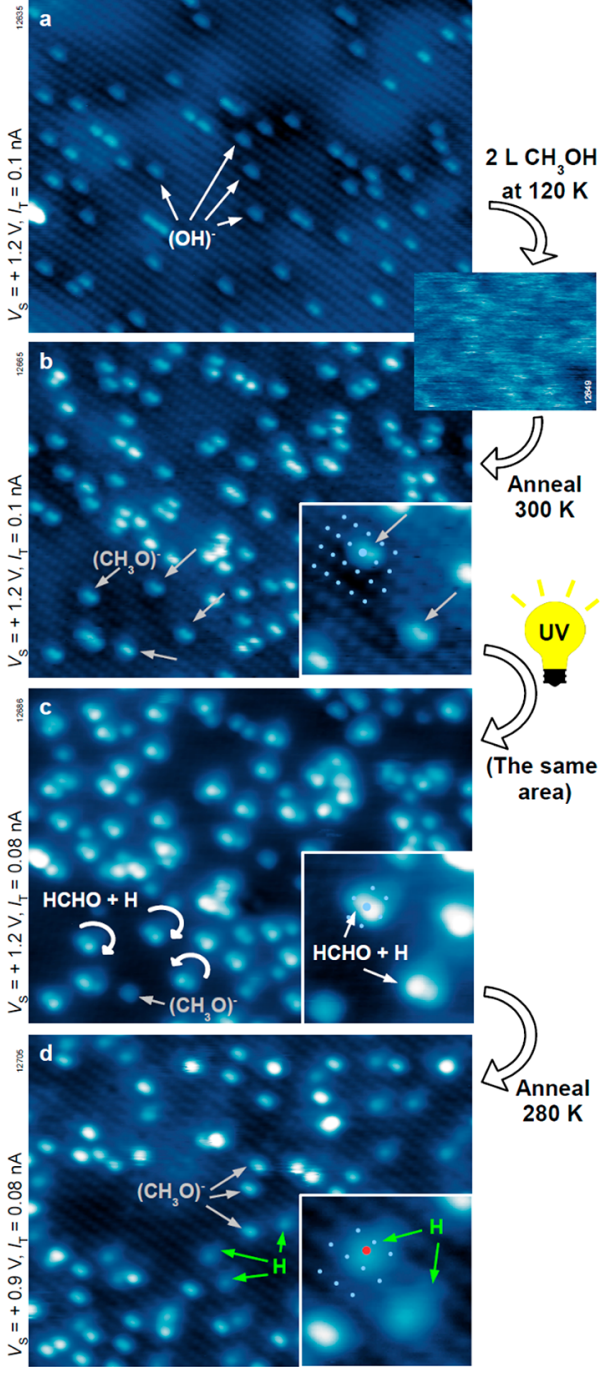

Figure 4. $20 \times 16 \mathrm{~nm}^{2}$ STM images of the anatase (101) surface, measured at $T=6 \mathrm{~K}$ : (a) Surface with terminal $(\mathrm{OH})^{-}$groups, prepared according to ref 53. (b) Methoxy $\left(\mathrm{CH}_{3} \mathrm{O}\right)^{-}$groups. The inset shows a zoom-in of two methoxy species. (c) The same area as in (b), after $30 \mathrm{~min}$ UV irradiation. The methoxy groups are partly converted to formaldehyde and $\mathrm{H}^{+}$. (d) Annealing to $280 \mathrm{~K}$ results in desorption of the formaldehyde; single $\mathrm{H}$ atoms are found at the surface. Dots in the insets mark approximate positions of surface $\mathrm{Ti}_{5 c}$ atoms.

Figure $4 \mathrm{a}$ shows a surface with terminal $(\mathrm{OH})^{-}$groups. Previously we have reported that the reaction between $\mathrm{O}_{2}$ and $\mathrm{H}_{2} \mathrm{O}$ coadsorbed on the anatase (101) surface results in the formation of these $(\mathrm{OH})^{-}$species, which are the only reaction product, and stable at room temperature. ${ }^{53}$ These species likely are present under realistic catalytic conditions, even though water molecules do not spontaneously dissociate on anatase. ${ }^{54}$ Water dissociation becomes possible via reaction with activated $\left(\mathrm{O}_{2}\right)^{-}$, where the excess electrons for oxygen activation ${ }^{55}$ either originate from sample doping (intrinsic/extrinsic), or from photoirradiation. The surface shown in Figure 4a was prepared by the same procedure as in ref 53, i.e., codosing $\mathrm{O}_{2}$ and $\mathrm{H}_{2} \mathrm{O}$ at $100 \mathrm{~K}$ and annealing to room temperature for $10 \mathrm{~min}$. This results in terminal $(\mathrm{OH})^{-}$; the concentration is determined by availability of excess electrons, here provided by $\mathrm{Nb}$ doping. This surface was then exposed to $2 \mathrm{~L}$ (Langmuir) of methanol at $T=110 \mathrm{~K}$. The corresponding STM image is shown in the inset between Figure $4 \mathrm{a}, \mathrm{b}$; only fuzzy images were obtained, (a)
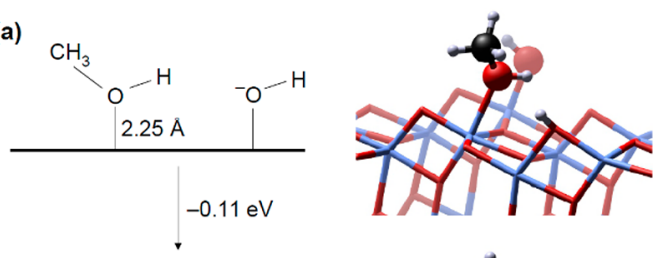

(b)
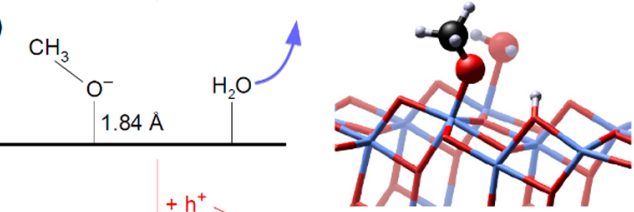

(c)

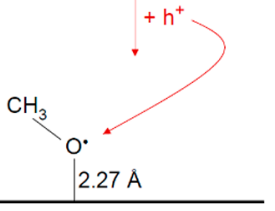

$-0.61 \mathrm{eV}$

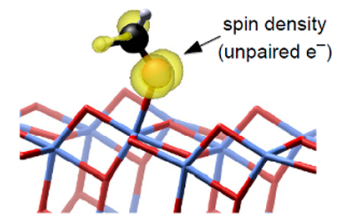

(d)
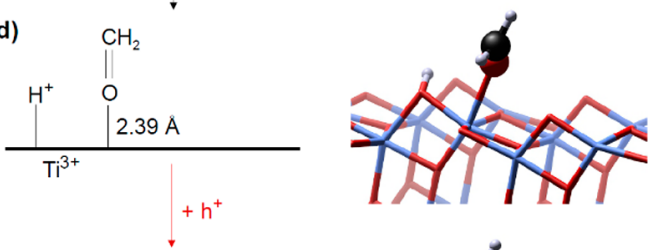

(e)

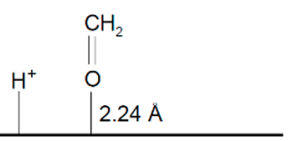

Figure 5. Reaction mechanism for the photoconversion of methanol to formaldehyde, obtained from B3LYP calculations. In step (a) $\rightarrow$ (b), methanol reacts with a terminal $\mathrm{OH}^{-}$group, which results in methoxy $\left(\mathrm{CH}_{3} \mathrm{O}\right)^{-}$. This step is thermally activated. In $(\mathrm{b}) \rightarrow(\mathrm{c})$, the methoxy accepts a hole, and a methoxy radical is formed. In (c) $\rightarrow$ (d), the methoxy radical is converted to formaldehyde and the excess hydrogen is transferred to the surface. (e) Adsorption geometry of the formaldehyde after hole-quenching of the excess electron coming from the neighboring bridging $\mathrm{OH}$ group. The extra hydrogen atom in (a) and (b) were included for computational purposes to maintain the cell neutrality.

which we attribute to mobility of the molecules weakly bound by a hydrogen-bonding network. It is indeed known that an STM tunneling current can easily switch hydrogen bonds, ${ }^{56,57}$ and thus, higher coverages of methanol appear unstable in STM images. Annealing such a surface to room temperature results in the reaction between coadsorbed $(\mathrm{OH})^{-}$and methanol (see Figure $4 \mathrm{~b}$ ). The proton from the methanol's $\mathrm{OH}$ group is transferred to the terminal $(\mathrm{OH})^{-}$, forming water and a methoxy anion $\mathrm{CH}_{3} \mathrm{O}^{-}$.

$$
\mathrm{CH}_{3} \mathrm{OH}+\mathrm{OH}^{-} \rightarrow \mathrm{CH}_{3} \mathrm{O}^{-}+\mathrm{H}_{2} \mathrm{O}
$$

The methoxy species (Figure 4b) appear as dimer-like protrusions with an apparent height of $\sim 60 \mathrm{pm}$, slightly higher than the $(\mathrm{OH})^{-}$species (typically $\sim 20 \mathrm{pm}$ ). The substrate around the methoxy species appears slightly darker in STM images, which is an indication for upward band-bending induced by the negative charge localized at the methoxy group. ${ }^{58}$ The second reaction product (i.e., water) is not present here, as it desorbs during prolonged annealing to 300 

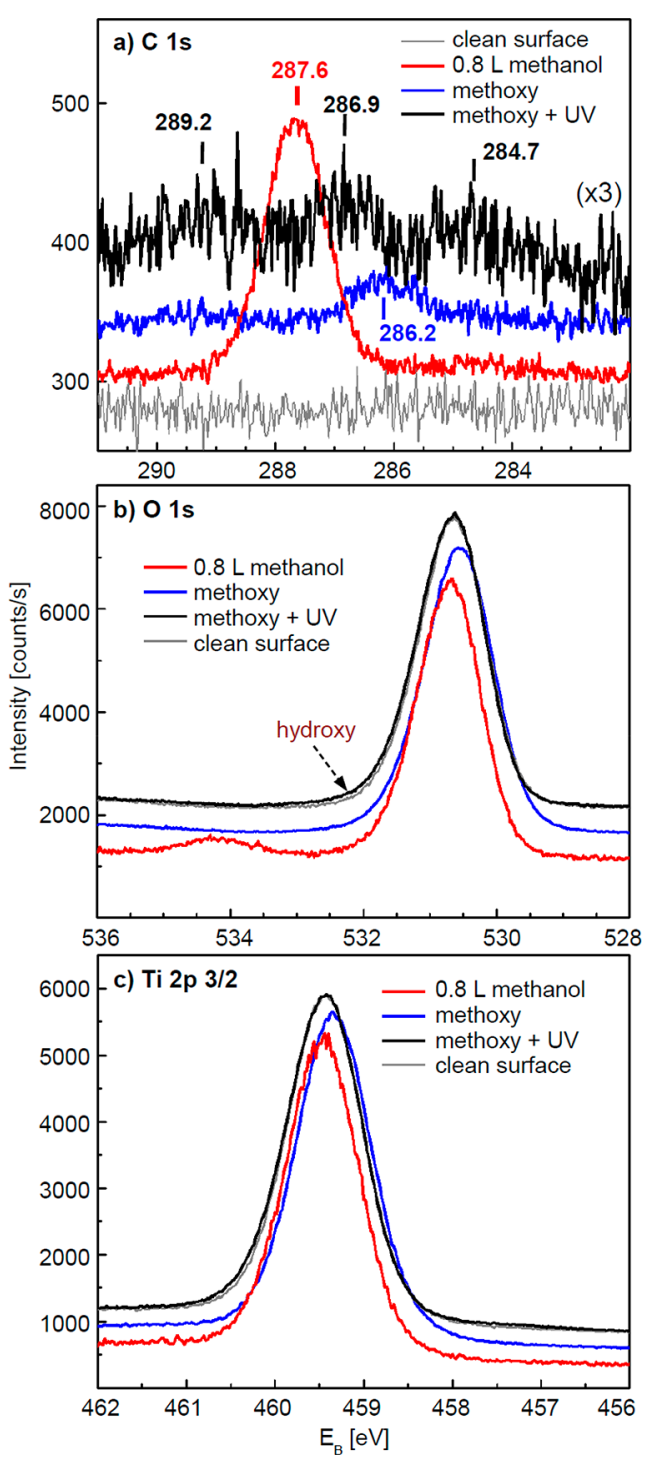

Figure 6. XPS spectra measured at $T=50 \mathrm{~K}$ after different steps of photoconversion of methanol to formaldehyde. (a) C 1s, (b) O 1s, (c) Ti $2 p_{3 / 2}$ peaks. Gray curves show a clean surface; red curves a surface exposed to $0.8 \mathrm{~L}(0.5 \mathrm{ML})$ methanol; blue curves a surface containing methoxy groups (created via thermal reaction with terminal $\mathrm{OH}^{-}$ groups); black curves show the methoxy groups after $30 \mathrm{~min}$ of UV irradiation ( $C$ 1s region magnified $3 \times)$.

$\mathrm{K}$, together with all unreacted methanol molecules (see the TPD results in Figure 1a).

The methoxy groups exhibit high photosensitivity. Figure 4c shows the surface after $30 \mathrm{~min}$ of UV irradiation (the same region as Figure 4b). Many of the methoxy groups change their appearance; their apparent height increases significantly (to $\sim 180 \mathrm{pm}$ ), and this new feature appears as a dimer, slightly rotated with respect to the Ti rows. We note that the STM images of the methoxy groups (Figure $4 \mathrm{~b}$ ) are very similar to the original terminal $\mathrm{OH}^{-}$groups (Figure 4a); the major difference lies in their interaction with UV light. The isolated $\mathrm{OH}^{-}$groups appear photoblind; they do not exhibit any change when exposed to UV light.

We considered various reaction pathways, and the best sequence is shown in Figure 5. The first step $(a \rightarrow b)$ is thermally activated: methanol is converted into a methoxy group $\left(\mathrm{CH}_{3} \mathrm{O}^{-}\right)$through interaction with a terminal $\mathrm{OH}^{-}$ group. This provides a slight energy gain of $0.11 \mathrm{eV}$, as the $\mathrm{OH}$ group has a higher proton affinity than the methoxy group. We note here that the key prerequisite for the methoxy formation is the presence of excess charge in the substrate (provided by extrinsic $\mathrm{Nb}$ doping in our experiments); the terminal $\mathrm{OH}^{-}$group would not form without an excess electron, and the reaction 1 could not happen. In the second step, the methoxy group accepts a hole (Figure 5, step $\mathrm{b} \rightarrow \mathrm{c}$ ), forming a methoxy radical $\mathrm{CH}_{3} \mathrm{O}^{\bullet}$. One $\mathrm{H}$ from the methyl group is hydrogen-bonded to the surface $\mathrm{O}_{2 \mathrm{c}}$ atom. The radical then decomposes into formaldehyde, and this $\mathrm{H}$ is transferred to the surface, forming a bridging $\mathrm{OH}$ group (Figure $5 \mathrm{~d}$ ). Experimentally we observe two orientations of the formaldehyde molecule (Figure 4c, with a detail in the inset), which we attribute to the fact that there are two possible sites for dropping the $\mathrm{H}$ atom at the surface. The STM images of formaldehyde in Figure 4c agree with STM images we obtained in a separate study of formaldehyde adsorption on the anatase (101) surface (apparent height of $160-180 \mathrm{pm}) .^{59}$

Figure 4d shows an STM image after further annealing to $280 \mathrm{~K}$ for $10 \mathrm{~min}$. Here the formaldehyde molecules have desorbed, ${ }^{59}$ and we observe single $\mathrm{H}$ atoms at the surface. We ascertained this observation by investigating the adsorption of atomic $\mathrm{H}$ on anatase (101) in detail (unpublished results, partially shown in the supplementary Figure S4). We identified the $\mathrm{H}$ atoms in Figure $4 \mathrm{~d}$ from their appearance in STM images $^{60}$ and by tip-induced manipulations. In addition to the hydrogen, Figure $4 \mathrm{~d}$ shows methoxy groups, which have not reacted under UV irradiation, as well as a few other species, which are not clearly identified.

Identification of the Species by XPS. While STM imaging is a powerful tool to observe processes directly at the atomic scale, the method provides very limited chemical information. All the species discussed in this work appear dimer-like close to the position of the surface Ti5c atoms, with subtle differences occurring mostly in the apparent height of the features. Typical apparent heights are $\sim 20 \mathrm{pm}$ for $\mathrm{OH}^{-}$ groups, $\sim 60 \mathrm{pm}$ for $\left(\mathrm{CH}_{3} \mathrm{O}\right)^{-}, \sim 120 \mathrm{pm}$ for methanol, and $\sim 180 \mathrm{pm}$ for formaldehyde. Typical experimental STM images, line profiles, and calculated STM images of these species are shown in Figure S5. These differences allow us to distinguish different species when they are present together in one STM image, and enable detection of the key photoinduced reaction steps. However, unambiguous chemical identification of the adsorbed species requires spectroscopic techniques. To this end, we have used XPS and TPD. We trace the identical reaction, as described in Figure 4. In order to minimize beam damage and sample contamination, the surface was freshly prepared after each XPS measurement.

The XPS results are summarized in Figure 6, which shows the $\mathrm{C} 1 \mathrm{~s}, \mathrm{O} 1 \mathrm{~s}$, and $\mathrm{Ti} 2 \mathrm{p}$ regions. The reference spectra obtained on the clean surface, free of any contamination and close to the stoichiometric condition, are shown in gray. The red spectra were measured after the surface was exposed to 0.8 $\mathrm{L}$ of methanol. The $\mathrm{C} 1 \mathrm{~s}$ peak is located at a binding energy of $287.6 \mathrm{eV}$, close to the value reported for methanol on $\mathrm{TiO}_{2}$ rutile (110) and (001) surfaces. ${ }^{14,61,62}$ Methoxy was prepared by an identical procedure as described in the context of Figure $4 \mathrm{~b}$, and the resulting spectra are shown in blue. The C $1 \mathrm{~s}$ spectrum shows a distinct peak at $286.2 \mathrm{eV}$, which we attribute to the methoxy species. Compared to the molecular methanol, the methoxy $\mathrm{C} 1 \mathrm{~s}$ peak is shifted by $1.4 \mathrm{eV}$ to lower binding energies. The typical shift between methanol and methoxy 
species adsorbed on oxide surfaces is only 0.4 to $0.6 \mathrm{eV}$, $63-67$ and rarely approaches $1.0 \mathrm{eV} .^{68,69}$ The shift observed here is considerably higher, yet not strong enough to attribute this peak to a different oxidation state of carbon.

In order to verify our assignment of the species in XPS, we performed DFT calculations of the core-level shifts with inclusion of the final-state effect; ${ }^{70}$ see details in Figure S6. We tested our setup on methanol/methoxy adsorbed on the rutile (110) surface, and we obtained C 1 s core-level shifts of 0.25 to $0.6 \mathrm{eV}$ (depending on the details of the computational model), while typical experimental values are $\sim 0.6 \mathrm{eV} .{ }^{14}$ The calculations performed on anatase provide significantly higher core-level shifts of 0.88 to $1.13 \mathrm{eV}$. When comparing these values to the experiment, it is necessary to further add the upward band-bending induced by the negatively charged methoxy species. The band bending is apparent in the $\mathrm{O} 1 \mathrm{~s}$ and $\mathrm{Ti} 2 \mathrm{p}$ core levels (Figure $6 \mathrm{~b}, \mathrm{c}$ ) and amounts to $0.2 \mathrm{eV}$. Taking this into account, the calculated core-level shifts show an excellent agreement with the experiment. The larger corelevel shift on anatase originates from the absence of an $\mathrm{H}$ bond between the $\mathrm{O}$ atom of the methoxy group and the dissociated proton. On other substrates the methanol dissociates, but there remains a hydrogen bond, which affects the electron distribution and results in different screening of the core-hole. The large shift in C 1s observed on anatase is therefore a finalstate effect. In the initial-state model, the difference in calculated core-level shifts between methanol and methoxy on anatase was only $0.22 \mathrm{eV}$.

The black curves in Figure 6 were measured after UV illumination of the methoxy species. Now the C 1s spectrum shows three peaks of similar intensity. The peak at $289.2 \mathrm{eV}$ corresponds to formaldehyde. ${ }^{59,71}$ The XPS spectrum after UV illumination contains two other peaks, located at 286.9 and $284.7 \mathrm{eV}$. The peak at $286.9 \mathrm{eV}$ can be attributed to unreacted methoxy groups. It is known that the formaldehyde produced during the photoreaction can couple to methoxy groups and form methyl formate $\left(\mathrm{CH}_{3}-\mathrm{O}-\mathrm{CHO}\right) .{ }^{10,14}$ The third $\mathrm{C}$ peak at $284.7 \mathrm{eV}$ could possibly originate from the methyl group of the methyl formate. 72

The $\mathrm{O} 1 \mathrm{~s}$ and $\mathrm{Ti} 3 \mathrm{p}$ peaks in Figures $6 \mathrm{~b}, \mathrm{c}$ show that formation of $\mathrm{OH}^{-}$and $\mathrm{CH}_{3} \mathrm{O}^{-}$leads to upward band bending $(\approx 0.2 \mathrm{eV})$, and the UV light completely removes the bandbending induced by the methoxy species. This is partially caused by neutralization of the negatively charged methoxy species by UV-generated holes. Further, the photoreaction produces hydrogen atoms bound to surface $\mathrm{O}_{2 c}$ atoms (socalled bridging hydroxyl groups). These act as electron donors ${ }^{5}$ in $\mathrm{TiO}_{2}$ and can thus contribute to the reduction of the bandbending. The presence of the bridging hydroxyls is indicated by the small shoulder on the high-binding energy side of the $\mathrm{O} 1 \mathrm{~s}$ peak (Figure 6b), supporting the assignment of the species in the STM image in Figure 4d.

TPD Results. In order to test the reaction schemes proposed above and add quantitative information, we have investigated the photo-oxidation of methanol by TPD. Here we show results for both ways of methanol activation: via reaction with terminal $\mathrm{OH}$ groups and with $\mathrm{O}_{2}$. In the case of methanol $+\mathrm{O}_{2}$, isotopically labeled ${ }^{18} \mathrm{O}_{2}$ was used. This suppresses the background signal and allows us to identify water originating from the reaction. Terminal $\mathrm{OH}$ groups were prepared by dosing $0.2 \mathrm{~L}^{18} \mathrm{O}_{2}$ at $55 \mathrm{~K}$, followed by dosing $1 \mathrm{~L}$ of $\mathrm{H}_{2}{ }^{16} \mathrm{O}$ and short annealing to $350 \mathrm{~K}$. This should provide normal and isotopically labeled ${ }^{16} \mathrm{OH}$ and ${ }^{18} \mathrm{OH}$ groups in a $\sim 1: 1$ ratio.
The TPD results are reported in Figure 7. The water signal coming from the reaction is shown in Figure $7 \mathrm{a}$. We have

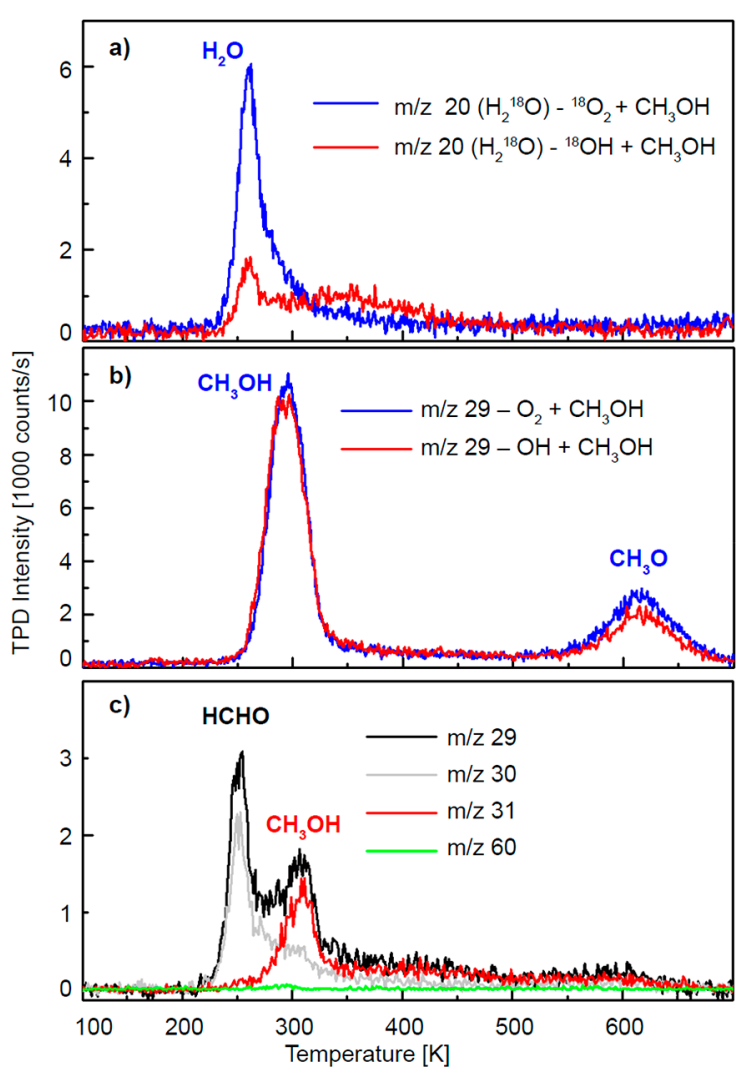

Figure 7. TPD spectra. (a) Signal of isotopically labeled water measured after codosing $0.5 \mathrm{ML}$ methanol with terminal $\mathrm{OH}$ groups, or with ${ }^{18} \mathrm{O}_{2}$. Here the terminal $\mathrm{OH}$ groups were obtained by codosing $0.5 \mathrm{ML} \mathrm{H}_{2}{ }^{16} \mathrm{O}$ with $0.5 \mathrm{ML}^{18} \mathrm{O}_{2}$ and annealing to $350 \mathrm{~K}$. (b) $\mathrm{CHO}^{+}$ signal measured during the same reaction. (c) Formaldehyde signal measured after illuminating the methoxy groups (created via the reaction with terminal $\mathrm{OH}$ groups) by $\mathrm{UV}$ light for $15 \mathrm{~min}$ at $T=100$ $\mathrm{K}$.

plotted the signal of isotopically labeled water, $m / z=20$, as it is not affected by the background signal. In the case of the reaction of methanol $+{ }^{18} \mathrm{O}_{2}$, a sharp desorption peak of labeled water is observed at $T=260 \mathrm{~K}$. This is the same temperature that is observed for $\mathrm{H}_{2} \mathrm{O}$ desorption from a clean surface, ${ }^{46}$ indicating that the whole reaction is completed below this temperature. For the case of $\mathrm{OH}$ reaction with methanol, the $\mathrm{H}_{2}{ }^{18} \mathrm{O}$ peak is smaller, with a pronounced shoulder extending up to $400 \mathrm{~K}$. We attribute the lower peak height to the fact that only half of the terminal $\mathrm{OH}$ groups is isotopically labeled. The shoulder indicates that the reaction 1 requires higher activation energy than the $\mathrm{O}_{2}$-mediated version.

The TPD spectra of the methoxy groups are shown in Figure $7 \mathrm{~b}$ where $m / z=29$ is plotted (methoxy desorbs as methanol and formaldehyde via a disproportiation reaction; ${ }^{7} \mathrm{~m} / z=29$ is a cracking product from both of these). The peak at $290 \mathrm{~K}$ corresponds to a cracking product from desorbing, unreacted methanol (the cracking pattern of this peak matches the cracking pattern of methanol, see Table S2). The methoxy peak is found at $615 \mathrm{~K}$. The peak heights are comparable for both pathways of methoxy formation, via activation with $\mathrm{O}_{2}$ and $\mathrm{OH}$, which indicates that the efficiency of the methoxy formation is similar in both cases. The reaction with $\mathrm{O}_{2}$ has a more complex 
pathway and is discussed in detail in the Supporting Information.

Figure 7c shows TPD traces of formaldehyde (the main cracking products are $m / z=29$ and 30) after illuminating the methoxy by UV light. Here the methoxy was created via the reaction with terminal $\mathrm{OH}^{-}$groups. The peak at $250 \mathrm{~K}$ corresponds to desorption of formaldehyde ${ }^{59}$ (highest sensitivity for $m / z=29$ ), while the peak at $310 \mathrm{~K}$ corresponds to methanol. We attribute the methanol desorption to a recombinative reaction between the methoxy that was not converted by the UV light, and the hydrogen produced during the methoxy photodecomposition. We can exclude that the methanol peak in Figure $7 \mathrm{c}$ would originate from background methanol pressure or from methanol remaining from the methoxy-creation step, as the methanol was dosed through the molecular beam only on the sample area. We also detect a tiny peak at mass $m / z=60$ at $290 \mathrm{~K}$, which was previously attributed to the methyl formate production; ${ }^{10,73}$ in this particular photoreaction, it is only a minor product.

Photoactivity of Methanol at High Coverages. Using STM, we have shown that isolated methanol molecules are not photoactive (Figure 3). However, we have found that dosing higher coverages of methanol and illuminating the surface by UV light results in production of methyl formate; see the TPD results in Figure 8a. While no methyl formate was detected for methanol coverages below $0.5 \mathrm{ML}$, the amount of methyl formate measured in TPD grows rapidly in the coverage range between 0.5 to $1.0 \mathrm{ML}$ and then saturates. We also evaluated the amount of methanol consumed in this photoreaction (see Figure $8 \mathrm{~b}$ ). To this end, we compared the amount of methanol dosed at the surface with the amount of methanol desorbing
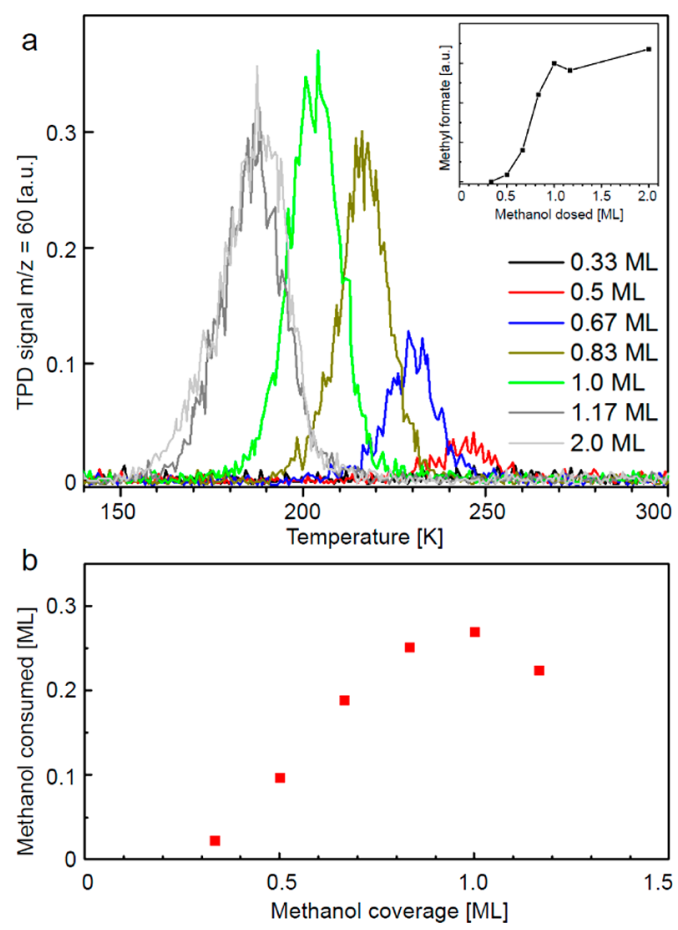

Figure 8. (a) TPD spectra of methyl formate $(m / z=60)$ after dosing various coverages of methanol and illuminating the surface by UV light for $30 \mathrm{~min}$ at $T=120 \mathrm{~K}$. The inset shows an integrated area of the $\mathrm{m} / \mathrm{z}$ $=60$ peak as a function of the methanol dosage. (b) The amount of methanol consumed in the photoreaction, obtained from an analysis of the TPD data at $m / z=31$. from the surface after the UV irradiation. (Here we used the TPD signal at $m / z=31$, and we took into account an appropriate correction stemming from the methyl formate cracking that contributes to the $m / z=31$ trace.)

In the high-coverage regime, our TPD data do not indicate the presence of any other products such as formaldehyde, $\mathrm{CO}$, or $\mathrm{CO}_{2}$ (further analysis of our TPD results is shown in Figures S7 and S8 and in ref 74). Previous studies on rutile and anatase report some formaldehyde desorbing after small UV exposures. $^{13,14}$ We did not detect the corresponding TPD peak, possibly because of the much higher UV doses used in this study. We note, however, that we detect $\mathrm{H}_{2} \mathrm{O}$ after the UV illumination (see Figure S8). Since $\mathrm{H}_{2} \mathrm{O}$ is not a reaction product of the methanol $\rightarrow$ methyl formate reaction, this indicates that there may be another reaction pathway in the high-coverage regime. Details are discussed in the Supporting Information.

DFT Calculations of the (Photo)Reaction Kinetics. We have shown that methanol can be activated by formation of methoxy groups or dosing high coverages; these two ways lead to different reaction products. Here we use DFT to explain the underlying mechanisms and show that the kinetics of the hole transfer plays a key role. First we discuss the simpler case of isolated $\mathrm{CH}_{3} \mathrm{O}^{-}$species and then move to the more complex situation in the high-coverage regime.

A photocatalytic reaction is a complex multistep event: ${ }^{1}$ (i) An electron-hole pair is generated upon absorbing a UV photon in the $\mathrm{TiO}_{2}$. (ii) The hole is transported to the surface. (iii) The hole is transferred from the $\mathrm{TiO}_{2}$ surface to the reacting species. (iv) The adsorbed species undergo a redox reaction. All these steps must proceed with a reasonable efficiency; the methoxy group outperforms methanol in several aspects.

Compared to methanol, the first advantage of the methoxy species is its negative charge. This induces band-bending in the near-surface region, resulting in an electric field inside the material, which splits the electron-hole pairs. It reduces the recombination probability and facilitates hole migration toward the surface. The main advantage of the methoxy group, however, lies in point (iii), i.e., the hole transfer between the substrate and the adsorbed species, as discussed in previous theoretical studies. ${ }^{75}$ There is a substantial difference in the hole transfer to the methoxy and methanol: while the transfer is energetically favorable for the methoxy, an isolated adsorbed methanol molecule is not capable of hole trapping because the presence of the proton bound to the $\mathrm{O}$ inhibits the hole transfer.

The last step of the reaction is the hydrogen transfer from the methoxy radical to the surface, resulting in the formaldehyde. It is important to consider that the relative stability of the methoxy radical with respect to its negatively charged version (i.e., the methoxy anion) largely depends on the availability of excess electrons in the sample. Our experiments have all been conducted on a reduced $\mathrm{TiO}_{2}$ sample, and thus, the methoxy $\rightarrow$ formaldehyde reaction competes with the backward reaction of accepting an electron from the substrate. We have estimated the energy barriers for the forward and the backward reactions (see Figure 9). The calculated barrier for the formaldehyde formation is $0.2 \mathrm{eV}$, while the energy barrier for the backward reaction is estimated to be at least $0.6 \mathrm{eV}$. The high activation barrier for the backward electron transfer largely originates from the significant structural reorganization associated with this reaction. The calculated bond length 

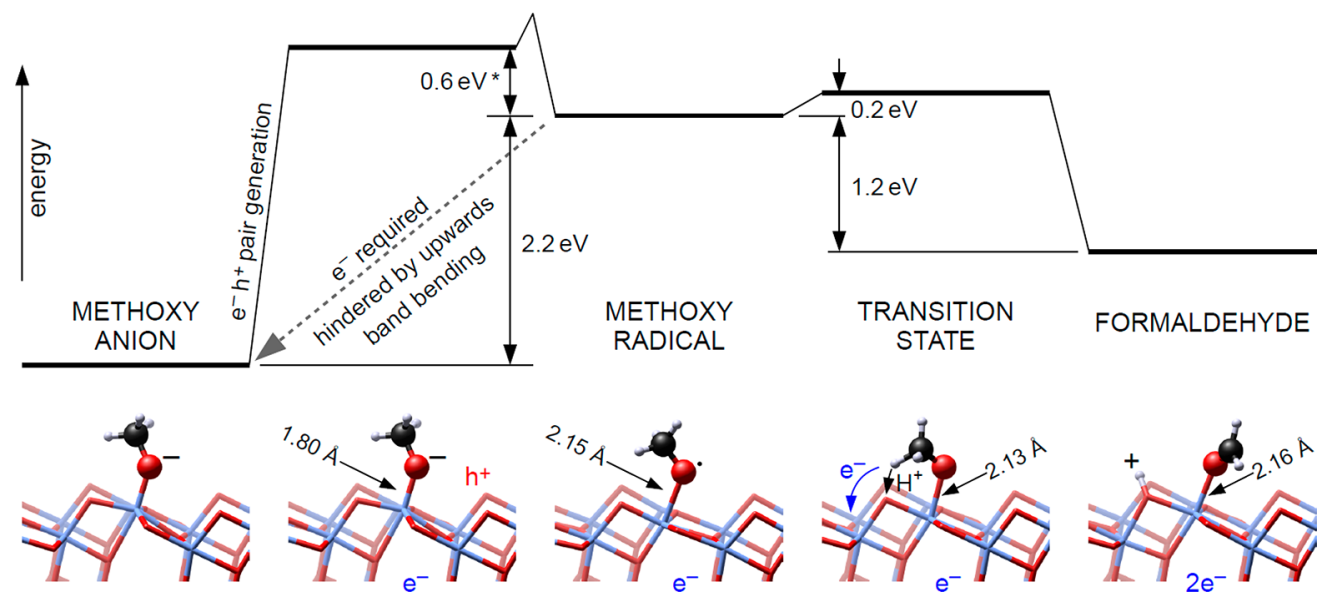

Figure 9. Calculated energy barriers for photoconversion of $\mathrm{CH}_{3} \mathrm{O}^{-}$(left) into formaldehyde (right). The $\mathrm{CH}_{3} \mathrm{O}^{-}$first accepts a hole, forming a methoxy radical (middle). This can either covert into formaldehyde with an energy barrier of $0.2 \mathrm{eV}$ or accept an electron from the $n$-doped $\mathrm{TiO}_{2}$; the backward reaction is hindered by the upward band bending and by an activation barrier. We consider that excess electrons are present in the sample by having a $\mathrm{Ti}$ atom substituted with a $\mathrm{Nb}$ atom, causing the presence of an extra electron $\left(\mathrm{e}^{-}\right)$. The energies are based on $\mathrm{PBE}+U$ calculations, except for the energy marked by asterisk, which is based on B3LYP.

between the methoxy radical and the surface $\mathrm{Ti}_{5 \mathrm{c}}$ is $2.15 \AA$ (see Figure 4c), while for the methoxy anion it is only $1.80 \AA$ (Figure $5 \mathrm{~b}$ ). This mechanism makes the photocatalytic reaction robust against recombination.

The situation in the high-coverage regime has quite different reaction kinetics. The coverage-dependent structure of methanol (Figure 2) plays a key role in understanding the qualitative change in the photoreaction; there is a qualitative change above the coverage of $0.5 \mathrm{ML}$. Below $0.5 \mathrm{ML}$, methanol adsorbs in a monodentate configuration with its $\mathrm{O}$ atom bound to the surface $\mathrm{Ti}_{5 \mathrm{c}}$ atom. Above $0.5 \mathrm{ML}$, there appears a different configuration where the molecule is only bonded by two hydrogen bonds. We will only focus on the first step of the photoreaction, that is, the hole transfer into an adsorbed methanol molecule, which is a key obstacle in its activation. The whole reaction pathway toward methyl formate is complex and contains various activation barriers; it is beyond the scope of this work.

We have investigated the process of hole transfer into the various adsorption configurations at 1.0 ML coverage (Figure 2c) by DFT calculations and compared the results to those obtained at $0.25 \mathrm{ML}$ coverage. Similar to the low-coverage results, we find that hole transfer does not take place for the lowest-energy adsorption configurations of Figure 2c, as hole transfer is possible only when the methanol molecule is partially dissociated (see Figure 10). The dissociated state is still energetically unfavorable by $+0.12 \mathrm{eV}$ at $1.0 \mathrm{ML}$ coverage (Figure 10c), although less than at low coverage, where the energy difference is $+0.21 \mathrm{eV}$ (Figure 10a).

In the presence of a hole, the situation is reversed and the dissociated state becomes energetically favored (Figure 10d). However, an analogous stabilization is observed also at low coverage (Figure $10 \mathrm{~b}$ ). So the question is why photoreactivity is only observed at high and not at low coverage? The reason is in the kinetics of the proton transfer processes. The activation barrier for proton transfer is as high as $+0.44 \mathrm{eV}$ for an isolated molecule, whereas it is only $+0.19 \mathrm{eV}$ when $1.0 \mathrm{ML}$ of methanol is present on the surface (see Figure 10). Also, in the presence of the hydrogen-bonding network at high methanol coverage, the proton transfer mechanism is different. The proton is not directly transferred from the molecule to the surface but is

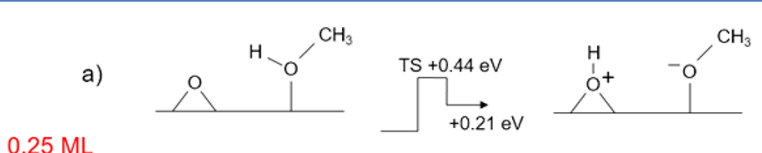

$0.25 \mathrm{ML}$

b)
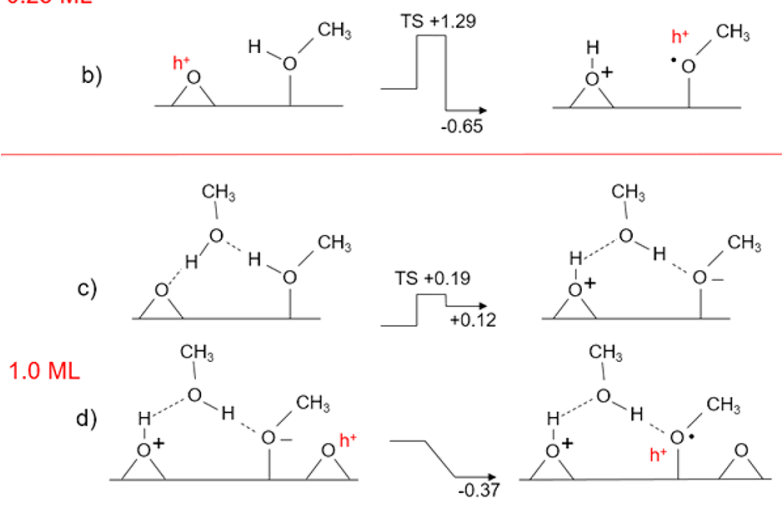

Figure 10. Schematic representation of methanol dissociation at low and high coverages ( 0.25 and 1.0 ML). Results in (a) and (c) are obtained in the absence of a photoexcited hole (PBE $+U$ calculations), whereas (b) and (d) include the presence of an excess hole (B3LYP calculations).

shuttled by a second methanol molecule through a concerted pathway, which is kinetically less demanding. An easier proton transfer facilitates the partial dissociation required for the hole transfer and the subsequent photochemical steps. Analogous calculations in the presence of a photoexcited hole in the lowcoverage regime $(0.25 \mathrm{ML})$ confirm that the proton transfer is the rate-determining step also in this situation (Figure 10b) and yields an activation barrier of $1.29 \mathrm{eV}$.

The mechanism of methanol photoconversion into methyl formate $\left(\mathrm{CH}_{3}-\mathrm{O}-\mathrm{CHO}\right)$ requires the removal of four protons. Many reaction pathways are therefore conceivable, and the reaction mechanism contains energy barriers. At the same time, we could not access the details of the reaction by STM; our attempts for imaging of high-coverage methanol layers only resulted in fuzzy images, as shown for example in Figure 4, inset between panels $a$ and $b$. We assume that the first hole transfer enables generation of formaldehyde, which cross-couples to methoxy groups that can easily form at methanol coverages 
above $0.5 \mathrm{ML}$ due to thermally activated processes. A very interesting fact in the high-coverage regime is that the photocatalytic methanol oxidation was reported to produce $\mathrm{H}_{2}$ as a byproduct. ${ }^{13}$ In contrast, the reaction scheme using $\mathrm{O}_{2}$ or $\mathrm{OH}^{-}$groups generates $\mathrm{H}_{2} \mathrm{O}$ due to the availability of activated oxygen.

It is worth mentioning that the coverage dependence of methanol photocatalysis on the anatase (101) surface reported in this work is exactly the opposite of that found on the rutile (110) surface. $^{20}$ There it was reported that the methanol photoactivity drops above $0.67 \mathrm{ML}$; this effect was attributed to methanol molecules hydrogen-bonded to surface bridging $\mathrm{O}_{2 \mathrm{c}}$ atoms. ${ }^{20}$ Further, a computational study showed that the energy balance for methanol dissociation on rutile turns in favor of the undissociated configuration at higher coverages, ${ }^{49}$ again opposite to the anatase case. This strongly indicates that the hydrogenbonding network within the first monolayer plays a key role in photocatalysis, and the exact arrangement of the hydrogen bonds is determined by the surface structure.

\section{CONCLUSIONS}

We have studied adsorption of methanol on the anatase (101) surface and its interaction with UV light. Isolated methanol molecules did not show any changes even after high exposures of UV irradiation. Two ways of methanol activation were identified: either via reaction with coadsorbed oxygen or terminal $\mathrm{OH}^{-}$groups or via dosing higher methanol coverages, above $\approx 0.5 \mathrm{ML}$. In the first case, the photoreaction results in the production of formaldehyde and water. In the latter case, methyl formate is produced; however, small amounts of water are also observed, suggesting that additional pathways may be present. In both scenarios, the key step for methanol photoactivation is its partial dissociation, i.e., methoxy formation. This is either obtained by transferring a proton to coadsorbed $\mathrm{OH}$ or $\mathrm{O}_{2}$, or it becomes feasible at higher methanol coverages where the kinetics of methanol dissociation is more favorable thanks to a "shuttled" proton transfer mechanism. Finally, it should be mentioned that identification of chemical species by their XPS core level shifts can be less straightforward than often assumed. Even for the lowest-energy (nonpolar) surfaces of two materials of identical chemical composition (rutile and anatase), the $\mathrm{C}$ 1s core level shift of adsorbed methanol versus methoxy differs by $0.8 \mathrm{eV}$ due to differences in $\mathrm{H}$ bonds and core-hole final-state screening.

\section{ASSOCIATED CONTENT}

\section{S Supporting Information}

The Supporting Information is available free of charge on the ACS Publications website at DOI: 10.1021/acscatal.7b02003.

Additional experimental data about (a) reaction of methanol with coadsorbed oxygen; (b) identification of surface $\mathrm{H}$ atoms in STM images; (c) appearance of methanol, methoxy, and formaldehyde in STM images; (d) calculations of C 1s XPS core level shifts for methanol and methoxy adsorbed on the anatase (101) and rutile (110) surfaces; and (e) additional TPD data from methanol photoreactions in the high-coverage regime (PDF)

\section{AUTHOR INFORMATION}

\section{Corresponding Authors}

*E-mail for M.S.: setvin@iap.tuwien.ac.at.
*E-mail for C.D.V.: cristiana.divalentin@mater.unimib.it. ORCID

Martin Setvin: 0000-0002-1210-7740

Cristiana Di Valentin: 0000-0003-4163-8062

Annabella Selloni: 0000-0001-5896-3158

Notes

The authors declare no competing financial interest.

\section{ACKNOWLEDGMENTS}

The work was supported by the European Research Council (ERC) advanced grant "Oxide Surfaces" (ERC-2011-ADG20110209), by the Austrian Science Fund (FWF) project Wittgenstein Prize (Z 250 Wittgenstein-Preis) and the FWF start grant Y847-N20. A.S. acknowledges the support of DoEBES, Division of Chemical Sciences, Geosciences and Biosciences under Award DE-SC0007347. C.D.V. acknowledges Cariplo Foundation for the Grant no. 2013-0615.

\section{REFERENCES}

(1) Linsebigler, A.; Lu, G.; Yates, J. T. Chem. Rev. 1995, 95, 735-758.

(2) Thompson, T. L.; Yates, J. T. Chem. Rev. 2006, 106, 4428-4453.

(3) Bai, Y.; Mora-Seró, I.; De Angelis, F.; Bisquert, J.; Wang, P. Chem. Rev. 2014, 114, 10095-10130.

(4) Fujishima, A.; Honda, K. Nature 1972, 238, 37-38.

(5) Diebold, U. Surf. Sci. Rep. 2003, 48, 53-229.

(6) Chen, X.; Mao, S. S. Chem. Rev. 2007, 107, 2891-2959.

(7) Henderson, M. A.; Otero-Tapia, S.; Castro, M. E. Faraday Discuss. 1999, 114, 313-329.

(8) Shen, M.; Henderson, M. A. J. Phys. Chem. Lett. 2011, 2, 27072710.

(9) Zhang, Z.; Bondarchuk, O.; White, J. M.; Kay, B. D.; Dohnalek, Z. Imaging Adsorbate $\mathrm{O}-\mathrm{H}$ Bond Cleavage: Methanol on $\mathrm{TiO}_{2}(110)$. J. Am. Chem. Soc. 2006, 128, 4198-4199.

(10) Phillips, K. R.; Jensen, S. C.; Baron, M.; Li, S.-C.; Friend, C. M. J. Am. Chem. Soc. 2013, 135, 574-577.

(11) Xiong, F.; Yu, Y.-Y.; Wu, Z.; Sun, G.; Ding, L.; Jin, Y.; Gong, X.Q.; Huang, W. Angew. Chem., Int. Ed. 2016, 55, 623-628.

(12) Guo, Q.; Xu, C.; Ren, Z.; Yang, W.; Ma, Z.; Dai, D.; Fan, H.; Minton, T. K.; Yang, X. J. Am. Chem. Soc. 2012, 134, 13366-13373.

(13) Xu, C.; Yang, W.; Guo, Q.; Dai, D.; Chen, M.; Yang, X. J. Am. Chem. Soc. 2013, 135, 10206-10209.

(14) Yuan, Q.; Wu, Z.; Jin, Y.; Xu, L.; Xiong, F.; Ma, Y.; Huang, W. J. Am. Chem. Soc. 2013, 135, 5212-5219.

(15) Lang, X.; Wen, B.; Zhou, C.; Ren, Z.; Liu, L.-M. J. Phys. Chem. C 2014, 118, 19859-19868.

(16) Tan, S.; Feng, H.; Ji, Y.; Wang, Y.; Zhao, J.; Zhao, A.; Wang, B.; Luo, Y.; Yang, J.; Hou, J. G. J. Am. Chem. Soc. 2012, 134, 9978-9985.

(17) Feng, H.; Tan, S.; Tang, H.; Zheng, Q.; Shi, Y.; Cui, X.; Shao, X.; Zhao, A.; Zhao, J.; Wang, B. J. Phys. Chem. C 2016, 120, 55035516.

(18) Hansen, J.; Bebensee, R.; Martinez, U.; Porsgaard, S.; Lira, E.; Wei, Y.; Lammich, L.; Li, Z.; Idriss, H.; Besenbacher, F.; Hammer, B.; Wendt, S. Sci. Rep. 2016, 6, 21990.

(19) Zhou, C.; Ren, Z.; Tan, S.; Ma, Z.; Mao, X.; Dai, D.; Fan, H.; Yang, X.; LaRue, J.; Cooper, R.; Wodtke, A. M.; Wang, Z.; Li, Z.; Wang, B.; Yang, J.; Hou, J. Chem. Sci. 2010, 1, 575-580.

(20) Yang, W.; Geng, Z.; Guo, Q.; Dai, D.; Yang, X. J. Phys. Chem. C 2017, 121, 17244-17250.

(21) He, Y.; Dulub, O.; Cheng, H.; Selloni, A.; Diebold, U. Phys. Rev. Lett. 2009, 102, 106105.

(22) Scheiber, P.; Fidler, M.; Dulub, O.; Schmid, M.; Diebold, U.; Hou, W.; Aschauer, U.; Selloni, A. Phys. Rev. Lett. 2012, 109, 136103.

(23) Setvin, M.; Aschauer, U.; Scheiber, P.; Li, Y. F.; Hou, W.; Schmid, M.; Selloni, A.; Diebold, U. Science 2013, 341, 988-991.

(24) Tuckerman, M. E.; Marx, D.; Klein, M. L.; Parrinello, M. Science 1997, 275, 817-820. 
(25) Fersht, A. R.; Shi, J.-P.; Knill-Jones, J.; Lowe, D. M.; Wilkinson, A. J.; Blow, D. M.; Brick, P.; Carter, P.; Waye, M. M. Y.; Winter, G. Nature 1985, 314, 235-238.

(26) Cleland, W. W.; Kreevoy, M. M. Science 1994, 264, 1887-1890.

(27) Yang, W.; Wei, D.; Jin, X.; Xu, C.; Geng, Z.; Guo, Q.; Ma, Z.;

Dai, D.; Fan, H.; Yang, X. J. Phys. Chem. Lett. 2016, 7, 603-608.

(28) Setvin, M.; Javorsky, J.; Turcinkova, D.; Matolinova, I.; Sobotik, P.; Kocan, P.; Ostadal, I. Ultramicroscopy 2012, 113, 152-157.

(29) Setvin, M.; Daniel, B.; Mansfeldova, V.; Kavan, L.; Scheiber, P.; Fidler, M.; Schmid, M.; Diebold, U. Surf. Sci. 2014, 626, 61-67.

(30) Pavelec, J.; Hulva, J.; Halwidl, D.; Bliem, R.; Gamba, O.; Jakub, Z.; Brunbauer, F.; Schmid, M.; Diebold, U.; Parkinson, G. J. Chem. Phys. 2017, 146, 014701.

(31) Halwidl, D. Development of an Effusive Molecular Beam Apparatus; Springer Spektrum: Berlin, 2016; pp 1-105.

(32) Giannozzi, P.; Baroni, S.; Bonini, N.; Calandra, M.; Car, R.; Cavazzoni, C.; Ceresoli, D.; Chiarotti, G. L.; Cococcioni, M.; Dabo, I.; Dal Corso, A.; de Gironcoli, S.; Fabris, S.; Fratesi, G.; Gebauer, R.; Gerstmann, U.; Gougoussis, C.; Kokalj, A.; Lazzeri, M.; Martin-Samos, L.; Marzari, N.; Mauri, F.; Mazzarello, R.; Paolini, S.; Pasquarello, A.; Paulatto, L.; Sbraccia, C.; Scandolo, S.; Sclauzero, G.; Seitsonen, A. P.; Smogunov, A.; Umari, P.; Wentzcovitch, R. M. J. Phys.: Condens. Matter 2009, 21, 395502.

(33) Perdew, J. P.; Burke, K.; Ernzerhof, M. Phys. Rev. Lett. 1996, 77, 3865-3868.

(34) Anisimov, V. I.; Zaanen, J.; Andersen, O. K. Phys. Rev. B: Condens. Matter Mater. Phys. 1991, 44, 943-954.

(35) Setvin, M.; Franchini, C.; Hao, X.; Schmid, M.; Janotti, A.; Kaltak, M.; Van de Walle, C. G.; Kresse, G.; Diebold, U. Phys. Rev. Lett. 2014, 113, 086402.

(36) Vanderbilt, D. Phys. Rev. B: Condens. Matter Mater. Phys. 1990, $41,7892-7895$.

(37) Henkelman, G.; Uberuaga, B. P.; Jonsson, H. J. Chem. Phys. 2000, 113, 9901-9904.

(38) Dovesi, R; Saunders, V. R.; Orlando, R.; Zicovich-Wilson, C. M.; Pascale, F.; Civalleri, B.; Doll, K.; Harrison, N. M.; Bush, I. J. CRYSTALO6 User's Manual; University of Torino: Torino, 2006.

(39) Becke, A. D. Phys. Rev. A: At., Mol., Opt. Phys. 1988, 38, 30983100.

(40) Lee, C.; Yang, W.; Parr, R. G. Phys. Rev. B: Condens. Matter Mater. Phys. 1988, 37, 785-789.

(41) Becke, A. D. J. Chem. Phys. 1993, 98, 5648-5652.

(42) Herman, G. S.; Dohnalek, Z.; Ruzycki, N.; Diebold, U. J. Phys.

Chem. B 2003, 107, 2788-2795.

(43) Tait, S. L.; Dohnalek, Z.; Campbell, C. T.; Kay, B. D. J. Chem. Phys. 2005, 122, 164707.

(44) Tait, S. L.; Dohnalek, Z.; Campbell, C. T.; Kay, B. D. J. Chem. Phys. 2005, 122, 164708.

(45) Campbell, C. T.; Sellers, R. V. Chem. Rev. 2013, 113, 41064135.

(46) Herman, G. S.; Dohnalek, Z.; Ruzycki, N.; Diebold, U. J. Phys. Chem. B 2003, 107, 2788-2795.

(47) Tilocca, A.; Selloni, A. J. Phys. Chem. B 2004, 108, 1931419319.

(48) Fransson, T.; Harada, Y.; Kosugi, N.; Besley, N. A.; Winter, B.; Rehr, J. J.; Pettersson, L. G. M.; Nilsson, A. Chem. Rev. 2016, 116, 7551-7569.

(49) Liu, S.; Liu, A.-A.; Wen, B.; Zhang, R.; Zhou, C.; Liu, L.-M.; Ren, Z. J. Phys. Chem. Lett. 2015, 6, 3327-3334.

(50) Setvin, M.; Hao, X.; Daniel, B.; Pavelec, J.; Novotny, Z.; Parkinson, G. S.; Schmid, M.; Kresse, G.; Franchini, C.; Diebold, U. Angew. Chem., Int. Ed. 2014, 53, 4714-4716.

(51) Setvin, M.; Buchholz, M.; Hou, W.; Zhang, C.; Stöger, B.; Hulva, J.; Simschitz, T.; Shi, X.; Pavelec, J.; Parkinson, G. S.; Xu, M.; Wang, Y.; Schmid, M.; Wöll, C.; Selloni, A.; Diebold, U. J. Phys. Chem. C 2015, 119, 21044-21052.

(52) Setvin, M.; Daniel, B.; Aschauer, U.; Hou, W.; Li, Y.-F.; Schmid, M.; Selloni, A.; Diebold, U. Phys. Chem. Chem. Phys. 2014, 16, 2152421530 .
(53) Setvin, M.; Aschauer, U.; Hulva, J.; Simschitz, T.; Daniel, B.; Schmid, M.; Selloni, A.; Diebold, U. J. Am. Chem. Soc. 2016, 138, 9565-9571.

(54) He, Y.; Tilocca, A.; Dulub, O.; Selloni, A.; Diebold, U. Nat. Mater. 2009, 8, 585-589.

(55) Setvin, M.; Hulva, J.; Parkinson, G. S.; Schmid, M.; Diebold, U. Proc. Natl. Acad. Sci. U. S. A. 2017, 114, E2556-E2562.

(56) Kumagai, T.; Shiotari, A.; Okuyama, H.; Hatta, S.; Aruga, T.; Hamada, I.; Frederiksen, T.; Ueba, H. Nat. Mater. 2012, 11, 167-172.

(57) Kumagai, T.; Kaizu, M.; Hatta, S.; Okuyama, H.; Aruga, T.; Hamada, I.; Morikawa, Y. Phys. Rev. Lett. 2008, 100, 161101.

(58) Ebert, P. Surf. Sci. Rep. 1999, 33, 121-303.

(59) Setvin, M.; Hulva, J.; Wang, H.; Simschitz, T.; Schmid, M.; Parkinson, G. S.; DiValentin, C.; Selloni, A.; Diebold, U. J. Phys. Chem. C 2017, 121, 8914-8922.

(60) Stetsovych, O.; Todorovic, M.; Shimizu, T. K.; Moreno, C.; Ryan, J. W.; Leon, C. P.; Sagisaka, K.; Palomares, E.; Matolin, V.; Fujita, D.; Perez, R.; Custance, O. Nat. Commun. 2015, 6, 7265.

(61) Farfan-Arribas, E.; Madix, R. J. Surf. Sci. 2003, 544, 241-260.

(62) Kim, K. S.; Barteau, M. A. Surf. Sci. 1989, 223, 13-32.

(63) Gamba, O.; Hulva, J.; Pavelec, J.; Bliem, R.; Schmid, M.; Diebold, U.; Parkinson, G. S. Top. Catal. 2017, 60, 420-430.

(64) Matolin, V.; Libra, J.; Skoda, M.; Tsud, N.; Prince, K. J.; Skala, T. Surf. Sci. 2009, 603, 1087-1092.

(65) Peng, X. D.; Barteau, M. A. Surf. Sci. 1989, 224, 327-347.

(66) Cox, D. F.; Schulz, K. H. J. Vac. Sci. Technol., A 1990, 8, 2599.

(67) Katsiev, K.; Harrison, G.; Alghamdi, H.; Alsalik, Y.; Wilson, A.; Thornton, G.; Idriss, H. J. Phys. Chem. C 2017, 121, 2940-2950.

(68) Au, C. T.; Hirsch, W.; Hirschwald, W. Surf. Sci. 1989, 221, 113130.

(69) Vohs, J. M.; Barteau, M. A. Surf. Sci. 1986, 176, 91-114.

(70) Pehlke, E.; Scheffler, M. Phys. Rev. Lett. 1993, 71, 2338.

(71) Yuan, Q.; Wu, Z.; Jin, Y.; Xiong, F.; Huang, W. J. Phys. Chem. C 2014, 118, 20420-20428.

(72) Giesbers, M.; Marcelis, A. T. M.; Zuilhof, H. Langmuir 2013, 29, $4782-4788$.

(73) Guo, Q.; Xu, C.; Yang, W.; Ren, Z.; Ma, Z.; Dai, D.; Minton, T. K.; Yang, Y. J. Phys. Chem. C 2014, 117, 5293-5300.

(74) Simschitz, T. Surface Studies of Photocatalytic Reactions of Methanol on $\mathrm{TiO}_{2}$ Anatase. Master's Thesis, TU Wien: Vienna, 2015. (75) Di Valentin, C.; Fittipaldi, D. J. Phys. Chem. Lett. 2013, 4, 19011906. 